Journal of the American Medical Association.

EDITED FOR THE ASSOCIATION BY N. S. DAVIS.

PUBLISHED WEEKLY.

$\begin{array}{lll}\text { Vol. V. Chicago, August 22, i } 885 . & \text { No. } 8 .\end{array}$

ORIGINAL ARTICLES.

\section{AN UNUSUAL CASE OF SUB-SEROUS FIBROUS TUMOR. ${ }^{1}$}

BY J. F. Y. PAINE, M. D.

PROFESSOR OF MATERIA MEDICA, THERAPEUTICS, HYGIENE AND CLINICAL MEDICINE, LOUISIANA, MEMBER OF THE TEXAS STATE MEDICAL SOCIETY, ETC.

It is not my intention, in the subjoined report, to disclose either a new therapeutic agent or an improved method of employing an old one, but simply to add a note to a procedure instituted by Hilderbrandt, and which already enjoys the sanction of our science. Without attempting a résumé of the literature of the subject, it is proper that I should state that the method has not met with universal favor, and it is partly for this reason that I venture to read the notes of a case of sub-serous fibrous tumors lately under my treatment.

Miss V. E. G., at. 43 years, native of I ouisana, of good social position, school teacher. Family history exceptionally clear. Personal health uninterrupted until about two years preceding my first visit. In the early part of 1882 the patient began to experience unaccustomed sensations, which soon developed into positive disorders, such as abdominal and pelvic pains, irritability of bladder and rectum, menorrhagia, leucorrhoea, etc. It was not until the early part of $\mathrm{r} 883$ that she discovered anything unusual in the contour of the abdomen. The presence of two hard masses, one in the hypogastrium, and the other in the right inguinal region, excited her aplohension, and she consulted a physician. From that period until January, 1884 , the tumors had grown with such rapidity that the abdominal cavity seemed filled to its utmost capacity. Not only were the viscera compressed and displaced, but the walls and integumentary tissues were so distended that she suffered almost constant pain. Both her attending and consulting physicians are prominent practitioners in Galveston, and I have no doubt that their management of her case is above criticism:' A frank prognosis on their part, however, determined her to dismiss them, and employ other counsel. It was at this juncture that I was called, and from which period my notes date.

My first visit was made on January 27 th, 1884 , and I was impressed by the ex-sanguined face, anxious

1 Read in the Section of Obstetrics and Gynecology, at the Thirtysixth Annual Meeting of the American Association. expression, rapid breathing, and feeble, unrhythmic pulse of my patient. Examination revealed an enormously distended abdomen, with skin so tight that it could not be pinched, and a hard, uneven surface. The uterus was decidedly retroverted, somewhat enlarged, and considerably below its normal plane. There were unmistakable evidences that pressure was impeding the functions of the bladder, kidneys, intestines, stomach, lungs and heart. Dyspncea and irregular heart-action caused great distress. The stom. ach was so compromised that only small quantities of food could be ingested, and even they were followed by various dyspeptic phenomena; the bowels were evacuated with difficulty; sleep was disturbed; pressure upon the sacral plexus gave rise to sciatica, which at times was agonizing. The patient was confined to her room, and a considerable proportion of the time to her bed. Exhausting menorrhagia occurred every month. Measurements of the circumference of the trunk at the epigastric, umbilical and hypogastric regions yielded $50,5 \mathrm{I}$ and $5 \mathrm{I} / 2$ inches. respectively. From that date, January soth, to Feb. roth prox., there was an increase of $I / 4$ inch for the first, $1 / 2$ inch for the second, and $1 / 2$ inch for the third region (adhering to the order in which they were first lamed).

On March I 6 th, thirty-five days after second and forty-nine after first measurements, there was a decrease of $4 \frac{1}{4}$ inches for the epigastric, $4 \frac{1}{2}$ for the umbilical and 5 for the hypogastric regions. Amelioration of every symptom was marked. Patient took more food, with less discomfort; slept better; was comparatively free from pain; menorrhagia was less pronounced ; was able to take a moderate amount of outdoor exercise, and, barring occasional hysterical paroxysms, has made uninterrupted progress.

April ist, sixteen days since tape-line was last applied, shows a loss of 4 inches for the first, 4 for the second, and 3 for the third region, and patient much improved in every respect.

May 2 Ist, fifty days, reveals a decline of ro inches for the first, 9 for the second, and 8 for the third region. With the exception of a few small abscesses, resulting from hypodermic medication, patient expresses herself as feeling "quite well."

July Irth, fifty-one days, discloses a falling off of $5 \frac{1}{2}$ inches for the first, $4^{1 / 2}$ for the second and $43 / 4$ for the third region. Patient feels so well that she enters upon a general round of visiting, returning calls made while she was confined to her room. On 
the 6 th of October she resumed her ciccupation of tions, carefully selected diet, well-regulated personal teacher in the public schools in this city, and has and house hygiene, and anodynes and hypnotics only lost one day, and that on account of sore throat. when indicated. I improvised an abdominal sup-

December $23 \mathrm{~d}$, ten months and twenty-seven days porter, which the patient wore when she sat up or after my first treatment, measurements displayed a walked, and it afforded great relief to the pelvic circumference of 24 inches against $50 \% / 4$ for the epi- viscera.

gastric, 30 against $5 \mathrm{I} / 2$ for the umbilical, and $30 \mathrm{in}-$ stead of $5^{2}$ for the hypogastric regions, exhibiting a difference of $26 \% / 4,21 / 2$ and 22 inches respectively. As far as could be ascertained, every function of her economy was normal, including menstruation. Mensurations taken to-day, April I8th, gave a still further slight decrement.

The treatment of this patient can be briefly stated. Ergot hypodermically was the only directly curative agent employed, but it was carried far beyond the limit advised by Hilderbrandt and others. I began with the daily use of the stereotyped dose of three grains of Squibbs' solid extract, diluted with a little glycerine and warm water, and so continued it for ten days, when my patient's increasing distress seemed to justify the administration of a like quantity morning and evening. From the eleventh day I increased the dose one grain each day, until ten grains were given morning and night. Slight signs of ergotism appearing, I did not increase the quantity further, but continued it in that degree until April ist (fifty-four days), when its evening exhibition was omitted. Ten grains daily at a single dose was maintained until May zist (fifty-one days), when the great shrinkage of the tumors, and disappearance of painful symptoms, led me to extend the interval to every other day. This latter order was pursued until July ir (fifty-one days), from which date to Dec. 23 d, the quantity employed was reduced to five grains, and the interval increased to three days. As previously stated, Squibbs' solid extract was the preparation selected, and the quantity used was freshly diluted with warm water at the time of using it. Less irritation was produced by fresh aqueous solutions than by others, however compounded, when allowed to stand a few days. 'The points of puncture were not restricted to any particular region, but a considerable extent of the surfaces of the trunk, upper and lower extremities were utilized first and last. The needle was variously introduced-obliquely into the subcutaneous areolar tissue, and straight down into the muscular structure -without appreciable difference in result as regards local irritation. Occasional abscesses developed in spite of every precaution.

None of the distressing symptoms of ergotism manifested themselves during the progress of the treatment. No gangrenous tendencies, no spasmodic complications; neither were there troublesome headache or vertigo. Nervous phenomena and nausea were the only symptoms which could be attributed to ergot. Hysterical paroxysms, however, had annoyed her from the beginning of her illness, and were no doubt in large measure due to exhaustion and reflex disturbance. The most notable effect of the ergot was slowing of the cardiac rhythm. The supplementary treatment consisted of blood, nerve and digestive tonics, rigid attention to all the func-

The patient visited the Exposition at New Orleans in the former part of January, during a very cold spell, and the combined influence of fatigue and chilliness gave a fresh impetus to the tumors; but within a month, under the same line of treatment already detailed, they had degenerated into insignificant, hardish masses. Five grains every four days is still employed. It cannot be urged that the rapid retrogression of these tumors is anywise the result of senile involution connected with the climacteric, for the patient had never suffered the slightest aberration of the menstrual function until menorrhagia was excited by these abnormal growths.

Galveston, Texas, April 2oth, I885.

\section{AUTOPLASTY; THE CONSERVATIVE SPIRIT OF MODERN SURGERY. ${ }^{1}$}

\section{BY F. FORMENTO, M. D.,} OF NEW ORLEANS, I.A.

The progress made in the science of medicine and surgery since the commencement of the present century has been wonderful indeed. The spirit of positivism and experimentation which characterizes our epoch, the generalization of clinical and practical studies, the great modern wars which have afforded such vast fields of observation, the most thorough knowledge of anatomy and physiology, and the immense improvement made in the physical and chemical sciences, satisfactorily explain the true and permanent advancement of medicine and surgery. Every day chemistry furnishes us with precise methods and new discoveries. The most wonderful and valuable of all has certainly been the discovery and generalization of anæsthesia, general and local, and particularly ether and chloroform, and the newly-discovered cocaine. These extraordinary agents, which have abolished pain, have permitted operations, such as ovariotomy, gastrotomy, the removal of internal tumors, and extensive autoplastic operations for ies toration or creation of organs, which, without anæsthesia, would never have been dreamed of.

Mechanics also offers to surgery new and valuable resources, incessantly inventirg and improvising instruments, apparatus, and physical appliances of all kinds. The use of India rubber, of solidified substances, such as plaster of Paris and silicate of potash, the introduction of metallic sutures and of the ecraseur, the application of the resources of uptics and acoustics, which allow us to see and hear into the depths of organs, and finally, the application of electricity and galvano-caustic, are as many innovations, every one of which has marked an epoch of progress and advancement in science. Thanks to the means and resources we now possess, is it surprising that

lRead in the Section on Surgery and Anatomy at the Thirty-Sixth Annual Meeting of the American Medical Association. 